\title{
Effect of Processing Parameters on the Mechanical Properties of Heavy Section Ductile Iron
}

\author{
Mohamed Mahmoud Mourad, Shimaa El-Hadad, \\ Mervat Mohamed Ibrahim, and Adel Abdelmonem Nofal \\ Central Metallurgical Research and Development Institute, P.O. Box 87, Helwan, Cairo, Egypt \\ Correspondence should be addressed to Shimaa El-Hadad; shimaam@yahoo.com
}

Received 10 September 2014; Accepted 2 January 2015

Academic Editor: Brij Kumar Dhindaw

Copyright (c) 2015 Mohamed Mahmoud Mourad et al. This is an open access article distributed under the Creative Commons Attribution License, which permits unrestricted use, distribution, and reproduction in any medium, provided the original work is properly cited.

\begin{abstract}
The main objective of the current work is to investigate the influence of different inoculation conditions on the microstructure and mechanical properties of heavy section ductile iron (DI) castings. Inoculation treatment was done via one step and double step treatments with different amounts of inoculants. The mechanical properties of the fabricated samples were evaluated. The best inoculation procedure in terms of graphite nodules characteristics and mechanical properties was double inoculation with $0.8 \%$ inoculants added at first and $0.2 \%$ in the late inoculation step. The presence of Sb in one of the cast alloys controlled the growth of graphite nodules in these heavy section ductile iron castings; however low impact toughness was recorded. The matrix structure of ductile cast iron showed a significant influence not only on the strength and impact properties but also on the fracture mode during testing.
\end{abstract}

\section{Introduction}

Wind power is a renewable, predictable, and clean source of energy. Substantial capacity can be built up quickly, offering the energy independence demanded by the world's largest and fastest-growing economies. The majority of wind turbine parts are made out of the challenging ductile iron grade ENGJS-400-18-LT [1]; examples of DI castings for windmill are shown in Figure 1. Therefore, attention is given for this grade of iron. The production of heavy section ductile iron castings, however, still faces real difficulties, represented in the formation of degenerated graphite morphologies in the ductile iron microstructures, which drastically reduces the impact as well as fatigue properties [2-4]. The requirements for high strength and high impact properties in DI at low temperatures for some applications as windmill are very strict. The European Standard EN-GJS-400-18U-LT commonly referred to as GGG 40.3 is an example. This standard not only has the normal mechanical requirements for ferritic iron but also specifies V-notched Charpy impact requirements of $12 \mathrm{~J}$ at $-20^{\circ} \mathrm{C}$ and minimum elongation of $18 \%$ [5]. In order to achieve these mechanical properties, the microstructure should be well controlled in terms of nodularity, nodule count, and matrix phases. This is because high nodule count impairs impact strength and low nodule count results in intercellular brittle phases which are detrimental to strength and ductility; see Figure 2. A minimum nodularity of $95 \%$ is critical; poorly shaped nodules act as stress riser and as initiation site for fracture under impact. Also, a matrix which is fully ferritic and free of cell boundary phases is important to satisfy the mechanical properties of windmill castings $[4,6]$.

Due to the increasing interest on sound heavy section DI castings and the controversial arguments about the foundry practice to control their microstructure (with particular reference to inoculation), this work is aimed at supporting the research about the influence of inoculation on microstructure and mechanical properties of heavy section DI castings. Though the section thickness in the current work is not comparable to that of the windmill, the experiments and the results of the present work give attention to some important points to be taken into consideration for casting of heavier sections of DI. 


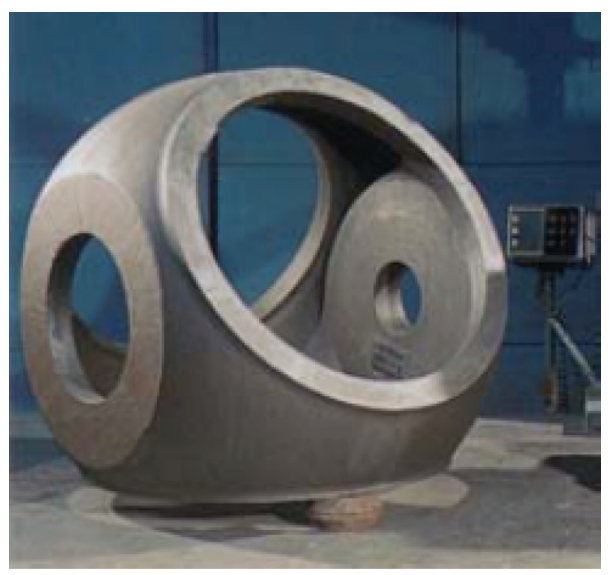

(a)

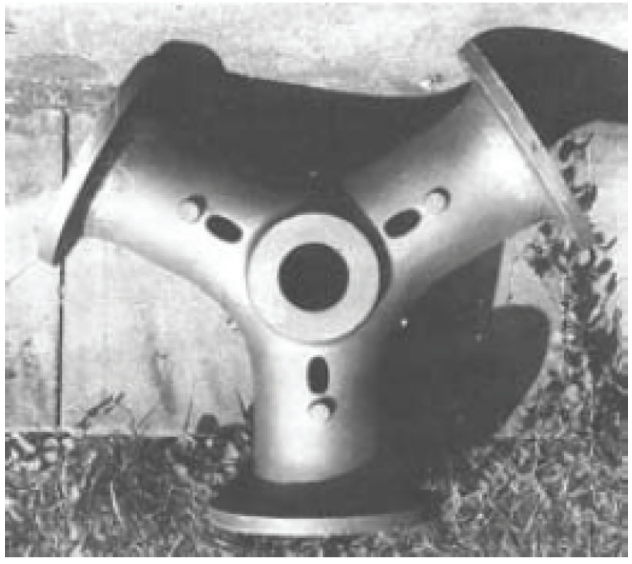

(b)

Figure 1: Ductile iron wind mill components, (a) hubs, (b) shaft.

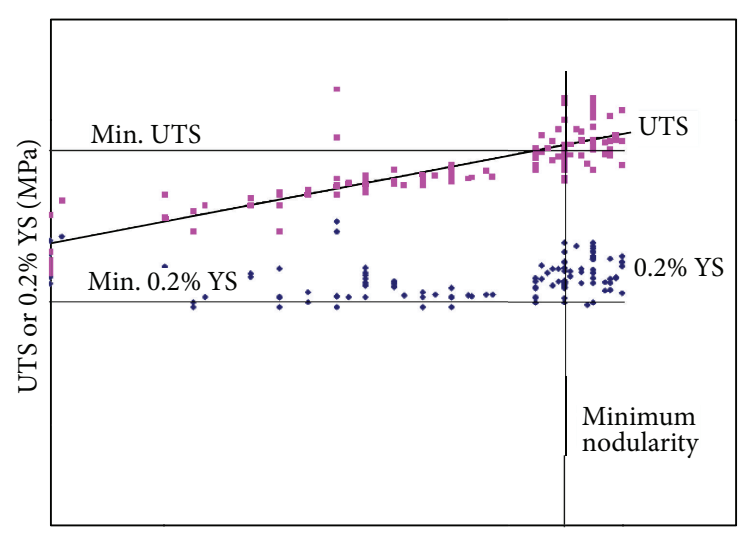

Nodularity (\%)

FIgURE 2: A plot representing UTS and YS, showing a drop in the property as the nodularity is reduced [9].

\section{Experimental Work}

2.1. Casting. A sand mould of cavity shaped as block of $400 \mathrm{~mm}$ length and $(100 \mathrm{~mm} \times 100 \mathrm{~mm})$ cross section was prepared. The moulds were made completely of sodium silicate bonded sand. A $100 \mathrm{~kg}$ charge, which consists of $80 \%$ sorel metal, $20 \%$ steel scrap, and the required amounts of carburizer and ferrosilicon alloy, was melted in a medium frequency induction furnace of $100 \mathrm{KW}, 100 \mathrm{Kg}$ capacity. The molten metal was poured at $1520^{\circ} \mathrm{C}$. The $\mathrm{Mg}$ treatment to obtain nodular graphite was performed using Vortex method with Fe-Si-Mg master alloy [7]. The molten metal was inoculated by foundry grade Fe-Si. Three different alloys were obtained depending on the inoculation method: alloy A was inoculated via one step with all the amount of inoculants added in the vortex, $0.5 \%$. Alloy B was inoculated in two steps; in the first step, half of Fe-Si quantity $(0.25 \%)$ was added in the vortex and the rest was added in the ladle which is known as (in-stream/in-mold) inoculation as the second step. In case of alloy C, $0.8 \%$ of the inoculants was added in the first step while $0.2 \%$ was added in the late inoculation step.
TABLE 1: Chemical composition of DCI alloys.

\begin{tabular}{lccccccc}
\hline \multirow{2}{*}{ Alloy number } & \multicolumn{7}{c}{ Chemical composition, Wt \% } \\
& $\mathrm{C}$ & $\mathrm{Si}$ & $\mathrm{Mn}$ & $\mathrm{P}$ & $\mathrm{S}$ & $\mathrm{Mg}$ & $\mathrm{Sb}$ \\
\hline $\mathrm{A}$ & 3.52 & 2.69 & 0.193 & 0.032 & 0.009 & 0.060 & - \\
$\mathrm{B}$ & 3.60 & 2.69 & 0.22 & 0.033 & 0.012 & 0.062 & - \\
$\mathrm{C}$ & 3.51 & 2.16 & 0.19 & 0.0232 & 0.0148 & 0.0421 & - \\
$\mathrm{D}$ & 3.69 & 2.58 & 0.309 & 0.029 & 0.006 & 0.044 & 0.02 \\
\hline
\end{tabular}

Though $\mathrm{Sb}$ is not a common additive in windmill DI castings, it is recommended in heavy section ductile iron castings because of its positive effect on graphite degeneration problem [8]. Therefore, another alloy D (double step, $0.5 \%$ inoculants) was cast where $0.02 \%$ of $\mathrm{Sb}$ was added intentionally to know the influence of $\mathrm{Sb}$ as a graphite antidegenerating element on the applicability of a DI alloy for windmill. The chemical composition of the four alloys expressed in mass content of the alloying elements is shown in Table 1.

In order to control the molten metal processing, thermal analysis was performed using the standard equipment necessary that consists of sand cup instrumented with a thermocouple connected to a microcomputer. The thermocouples were placed in the middle part of the cup. The obtained cooling curves were used as a guide during the casting process.

2.2. Microstructure Investigation. The samples were cut of the produced blocks A, B, C, and D for metallographic examination. The quantitative analysis was performed for each sample and the average values of graphite nodularity and nodule count were considered. This was done using image analysis software.

2.3. Mechanical Testing. The tensile test was performed using a tensile test machine at a loading rate of $10 \mathrm{~mm} / \mathrm{min}$. Three tensile test samples shaped according to (ASTM E8) were used for each alloy of A-D. The average values of the yield strengths, tensile strengths, and elongations were calculated. 


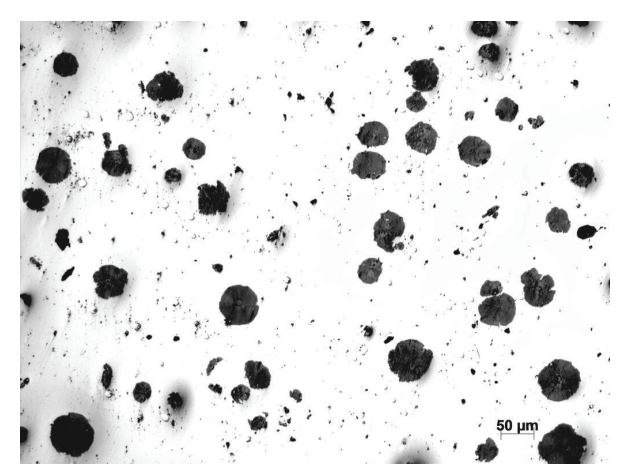

(a)

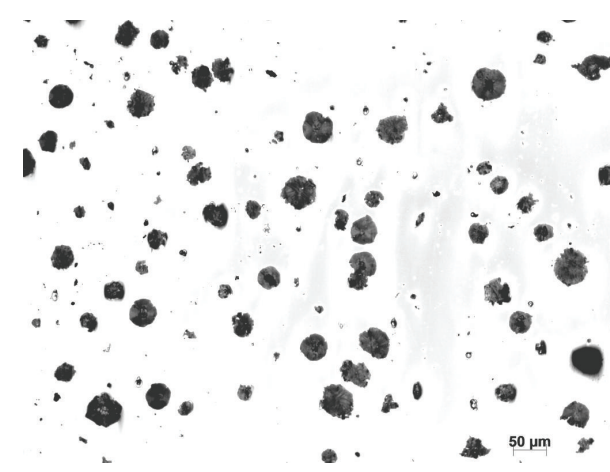

(c)

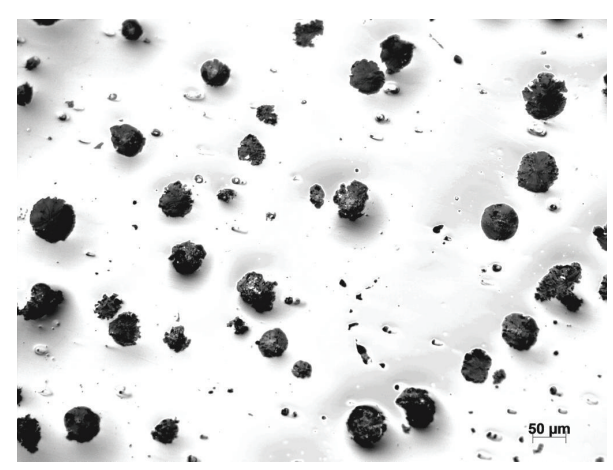

(b)

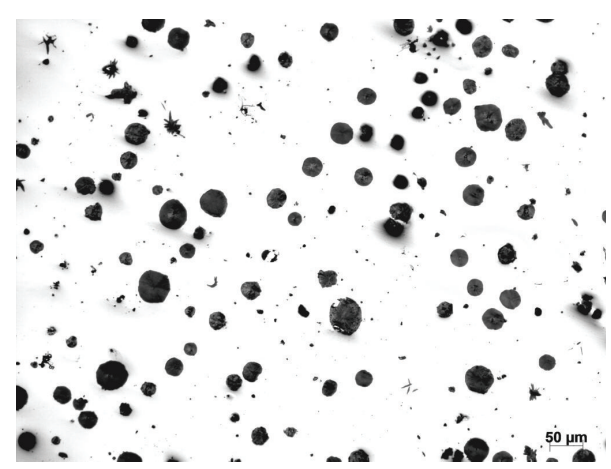

(d)

Figure 3: Optical micrographs (before etching) of the four DI alloys (a) A, (b) B, (c) C, and (d) D.

After the test, the topography of the fracture surface was investigated using scanning electron microscopy. An instrumented impact test machine using notched samples was used. The impact strength was evaluated according to ASTM-E23. An average of five readings was considered.

\section{Results and Discussion}

3.1. Microstructure of As-Cast Samples. The microstructures of the as-cast samples A, B, C, and D before and after etching are shown, respectively, in Figures 3 and 4. In all the micrographs shown in Figure 3, homogeneity of graphite in the matrices is observed. After etching with nital, they present different microstructures depending on the pearlite content in the matrix, Figures 4(a)-4(d). The corresponding quantitative analysis of graphite nodules count and nodularity is summarized in Table 2.

The one step inoculation (A), Figure 3(a), resulted in a considerably low nodularity of about $70 \%$ and nodule count of $40 \%$. The amount of pearlite in the microstructure was around 2\%, Figure 4(a). Using the double step inoculation ( $0.5 \%$ inoculant), alloy $\mathrm{B}$ did not show notable change in nodule count or in the nodularity. This is a disadvantage considering the high nodule count required for some applications like wind mill (not more than $100-200 / \mathrm{mm}^{2}$ ). Following the recommended double step inoculation from the industrial expertise [7], 0.8\% inoculants were added in the first step and $0.2 \%$ at the mold. In this case, a significant improvement in
TABLE 2: Microstructure description of the DCI alloys.

\begin{tabular}{ll}
\hline Alloy & Microstructure description \\
\hline A & Matrix $98 \%$ ferrite, $2 \%$ pearlite \\
& Nodularity $70 \%$, nodule count $40 / \mathrm{mm}^{2}$ \\
\hline B & $\begin{array}{l}\text { Matrix } 95 \% \text { ferrite, } 5 \% \text { pearlite } \\
\text { Nodularity around } 71 \% \text {, nodule count } 40 / \mathrm{mm}^{2}\end{array}$ \\
\hline C & Almost fully ferritic matrix \\
& Nodularity around $95 \%$, nodule count $80 / \mathrm{mm}^{2}$ \\
\hline D & Matrix $2 \%$ ferrite, $98 \%$ pearlite \\
& Nodularity $98 \%$, nodule count $80 / \mathrm{mm}^{2}$ \\
\hline
\end{tabular}

the graphite nodularity of about $95 \%$ was achieved and the nodule count was increased from 40 to $80 / \mathrm{mm}^{2}$. On the other hand, alloy $\mathrm{D}$ containing $0.02 \% \mathrm{Sb}$ could achieve the best nodularity of $98 \%$ and nodule count was almost the same as alloy C.

Referring to Zhe et al. [8, 11], appropriate content of antimony addition plays a significant role in increasing the nucleation rate and inhibiting the deterioration of graphite nodules in heavy section ductile iron castings. This is due to the fact that $\mathrm{Sb}$ surrounds the graphite nodule and prevents the carbon diffusion from the matrix to the nodules as shown in the line scan and elemental map of Figure 5. However, in the presence of $\mathrm{Sb}$, the matrix is almost fully pearlitic; containing fine and coarse pearlite lamellas. This percentage 


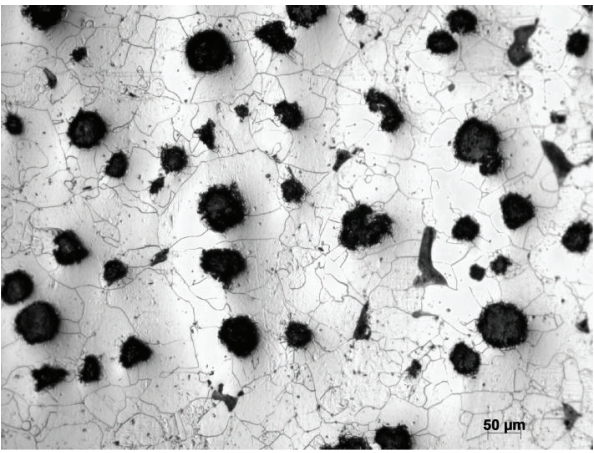

(a)

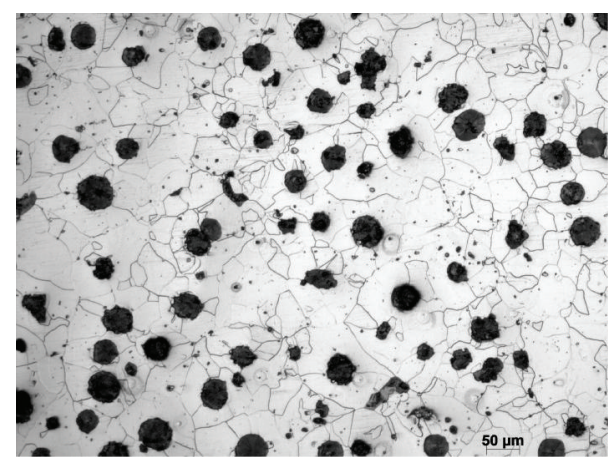

(c)

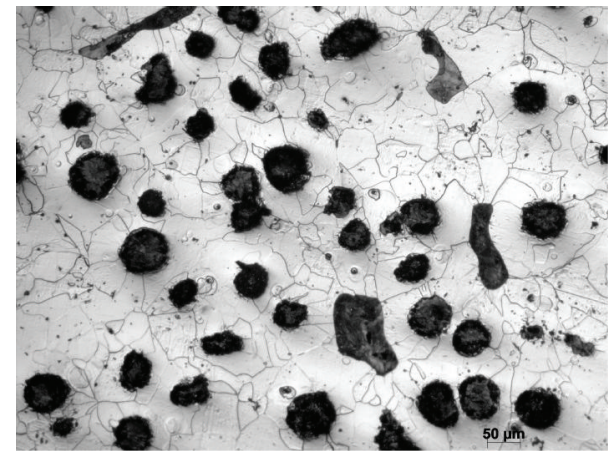

(b)

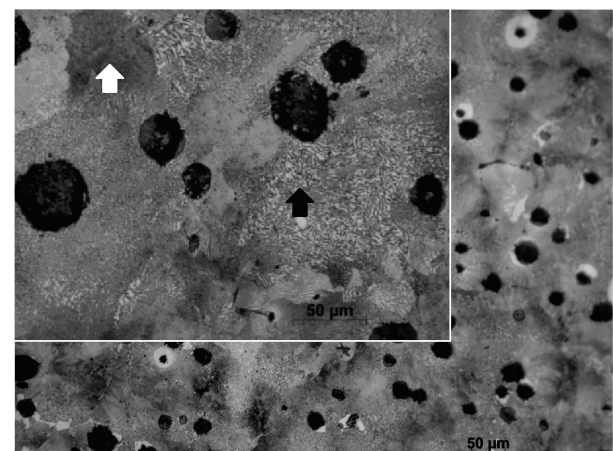

(d)

FIgURE 4: Optical micrographs (after etching) of the four DI alloys (a) A, (b) B, (c) C, and (d) D.

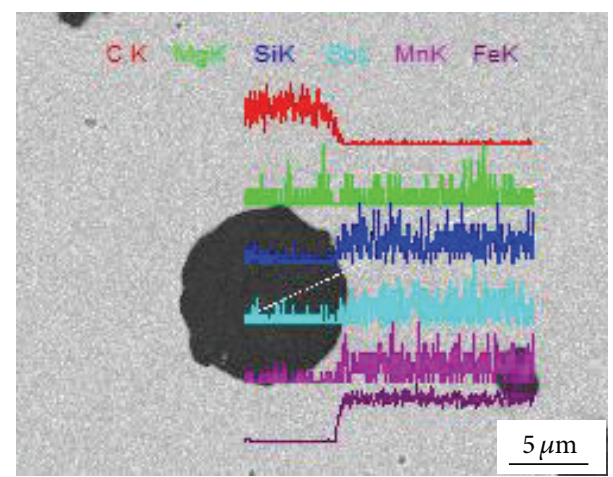

(a)

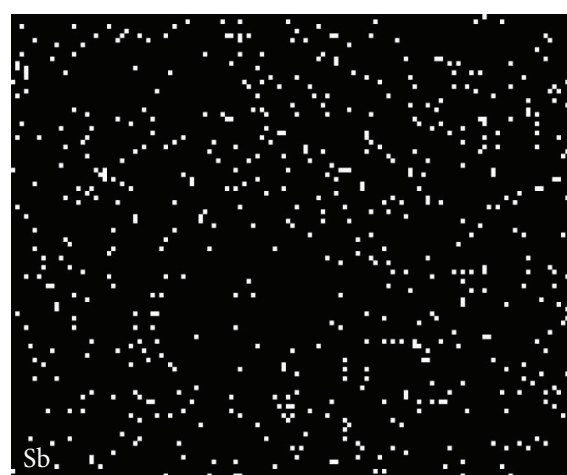

(b)

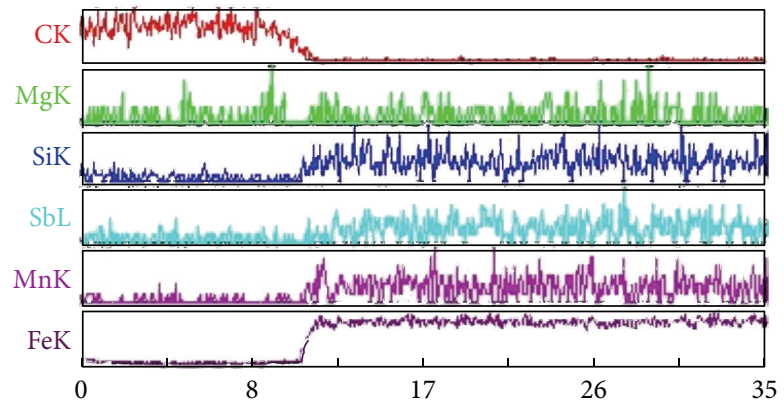

(c)

FIGURE 5: Line scan and elemental map of alloy D sample showing the distribution of Sb around a graphite nodule. 


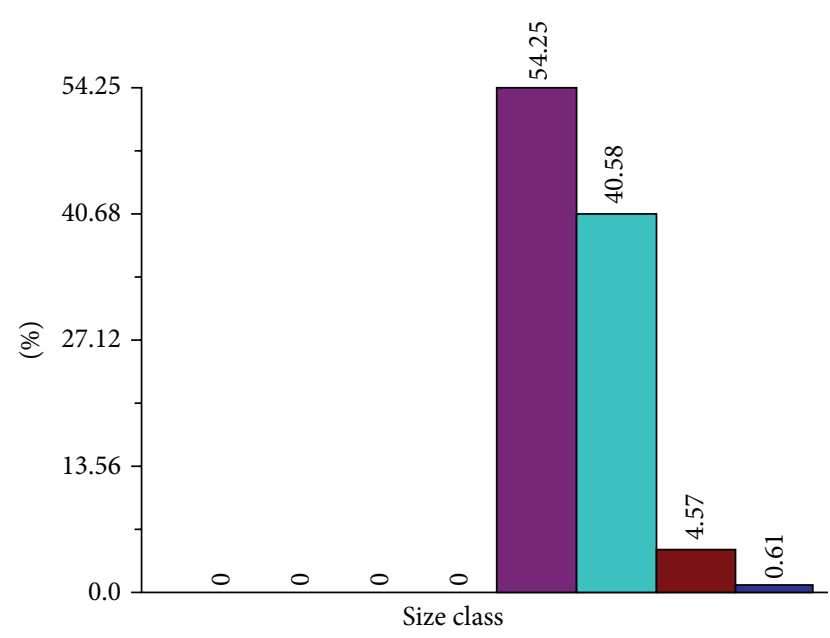

(a)

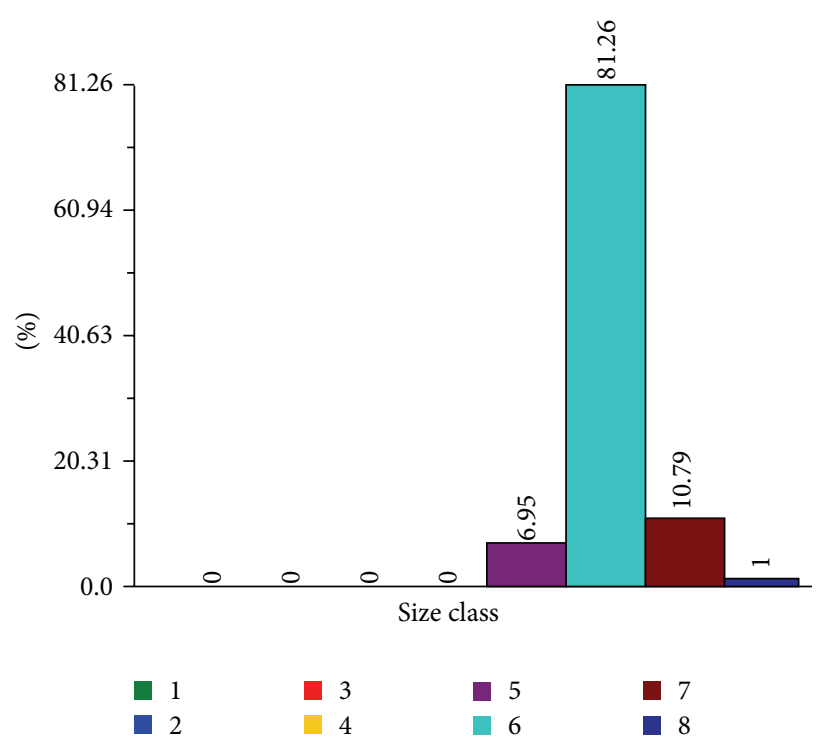

(c)

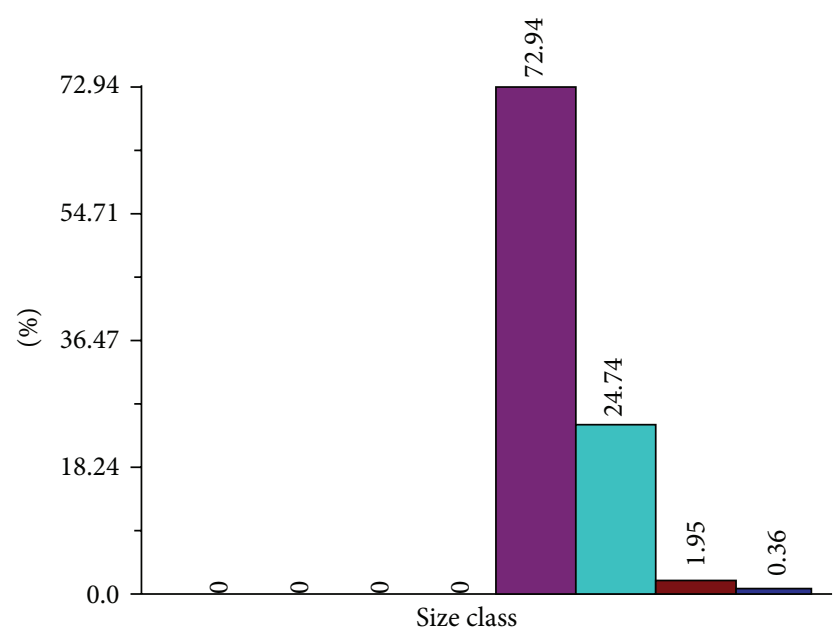

(b)

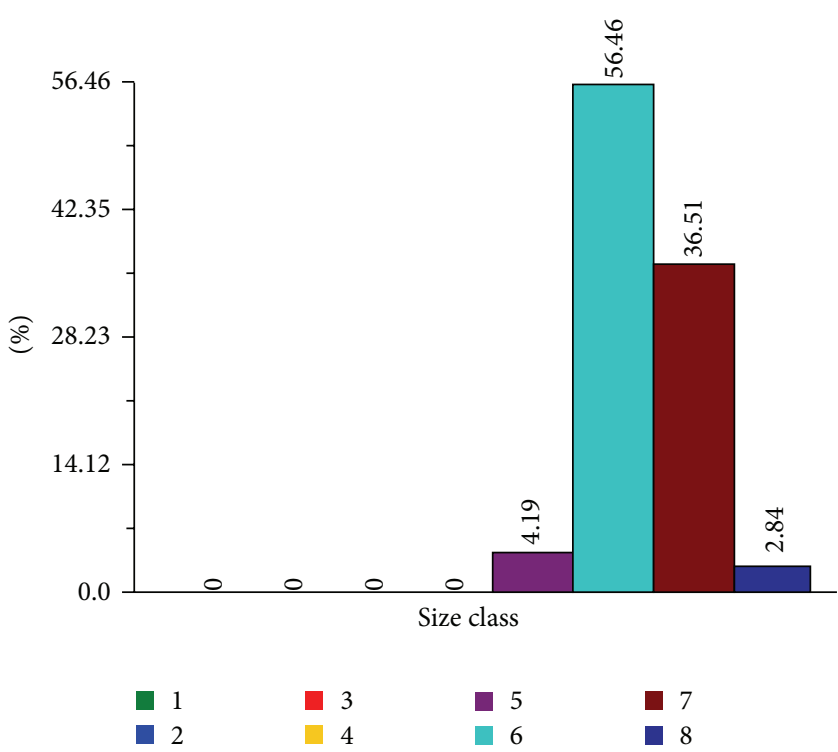

(d)

Figure 6: Distribution of particles size in alloys A, B, C, and D, respectively.

of pearlite is detrimental in terms of the subzero impact toughness required for this application, especially in the cold regions. Comparing Figures 3(a) and 3(b) to Figures 3(c) and $3(\mathrm{~d})$, it is clear that the size of graphite nodules was increased in alloys A and B which resulted in relatively lower nodule counts. This can be further confirmed by the nodules size distribution carried out by image analyzer and represented in Figure 6. According to the nodules size classification [9] for ductile iron casting, shown in Figure 7, the largest nodule takes grade $3(25-50 \mathrm{~mm})$ while the smallest one (less than $1.5 \mathrm{~mm}$ ) is graded as 8. In case of alloys A and B, the particles of grade $5(6-12 \mathrm{~mm})$ represented the majority among all sizes. On the other hand, most of the nodules in alloys $\mathrm{C}$ and $\mathrm{D}$ were of grade $6(3-6 \mathrm{~mm})$. When the nodules combine together, their size increased and their count accordingly decreased.
3.2. Thermal Analysis. Thermal analysis was performed in order to compare the solidification behavior of the melt after the different inoculation conditions. Figures 8 and 9 are magnified parts of the cooling curves showing the eutectic and eutectoid reactions, respectively, in the different alloys. Some characteristic temperatures calculated from the cooling curves by means of the first time-derivative are shown in Table 3. The characteristic temperatures are denoted by $T_{\text {eu }}$ for the eutectic temperature (undercooling) and $T_{\mathrm{Re}}$ for the maximum bulk eutectic temperature (recalescence). Recalescence rate was also calculated as $T_{\mathrm{Re}}$ divided by $T_{\mathrm{eu}}$. Comparing $T_{\text {eu }}$ and $T_{\mathrm{Re}}$ values of Figures $8(\mathrm{a})-8(\mathrm{~d})$, it is clear that the different inoculation procedures influenced both of the eutectic undercooling and the recalescence temperatures. The one step inoculation, alloy (A), showed the lowest $T_{\text {eu }}$ and $T_{\mathrm{Re}}$ as presented in Table 3. On the other hand, the double 

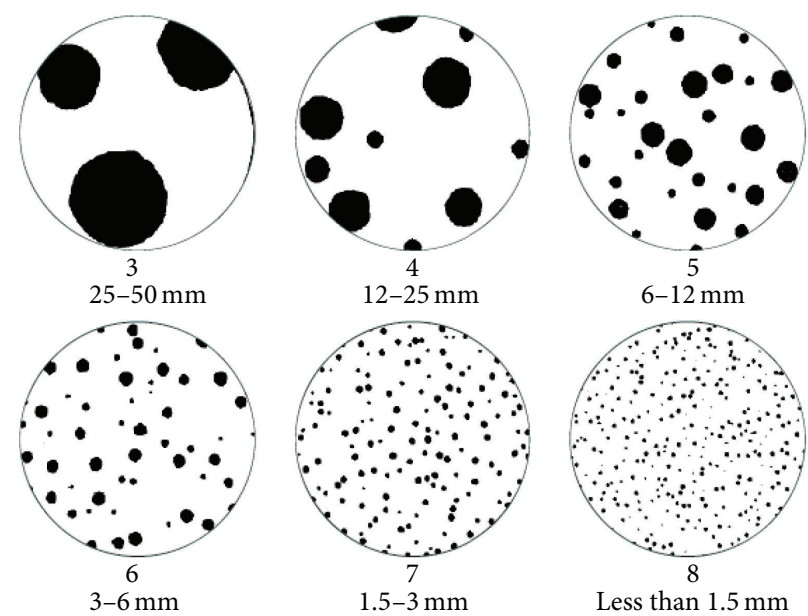

FIGURE 7: Graphite size classes in ductile iron [10]. Diagrammatic representations of the standard graphite nodule sizes in ductile iron at $\times 100$ magnification (from VI).

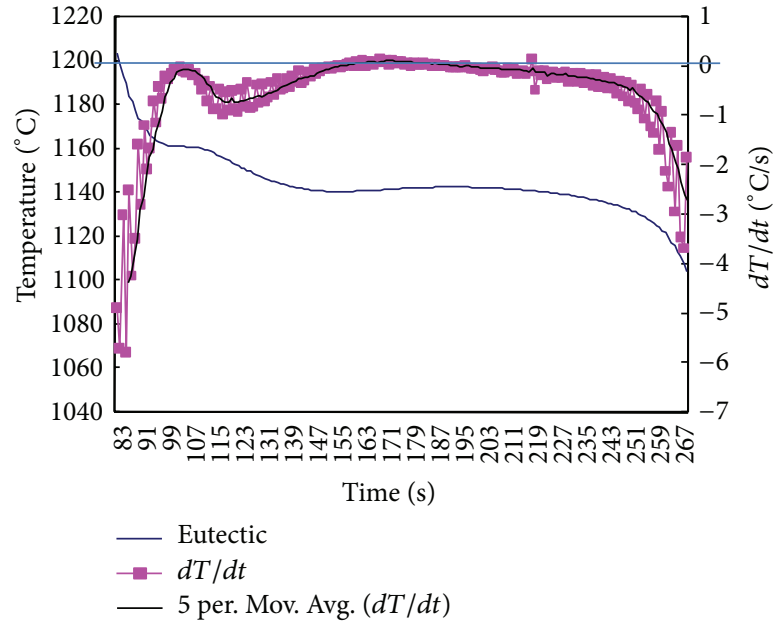

(a)

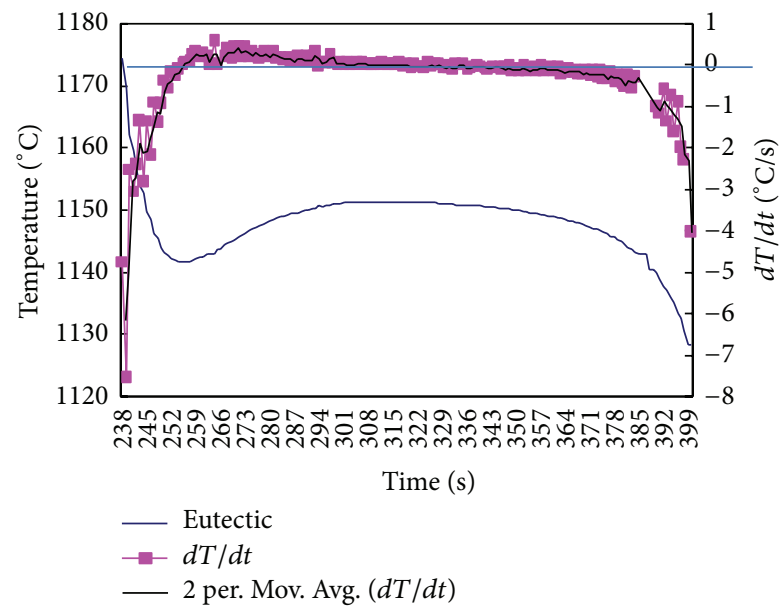

(c)

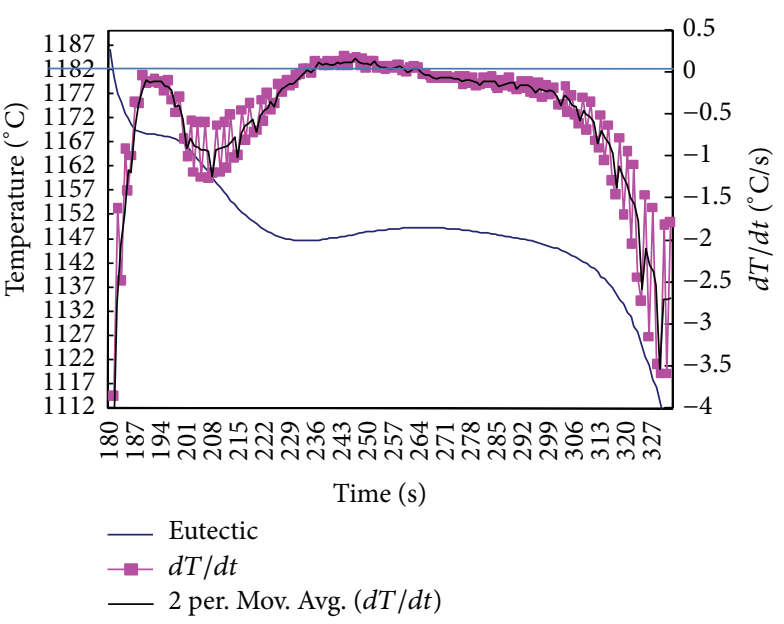

(b)

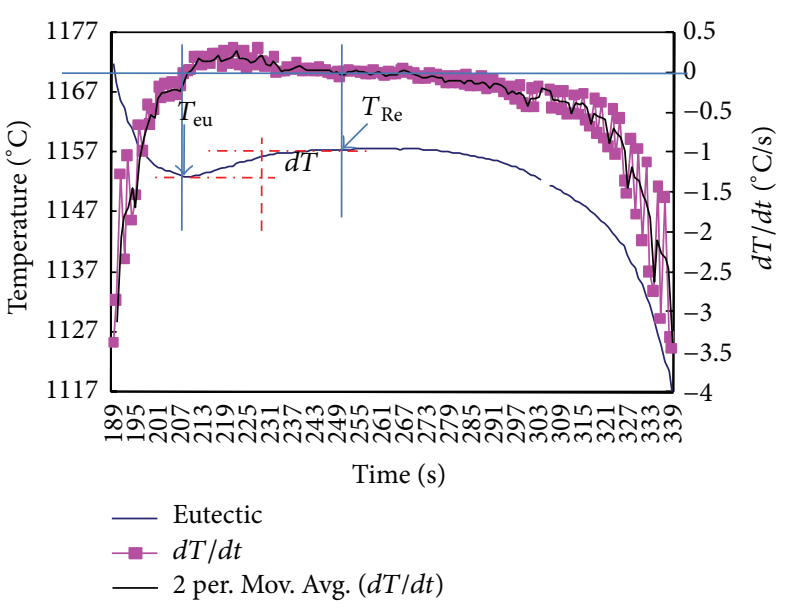

(d)

Figure 8: Magnified part of the cooling curves showing the change in the amount of eutectic undercooling of the DI alloys (a) A, (b) B, (c) $\mathrm{C}$, and (d) D. 


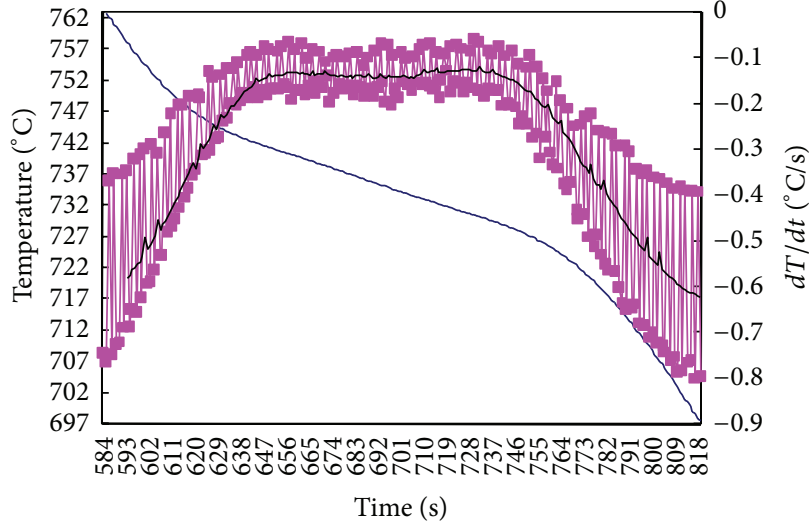

(a)

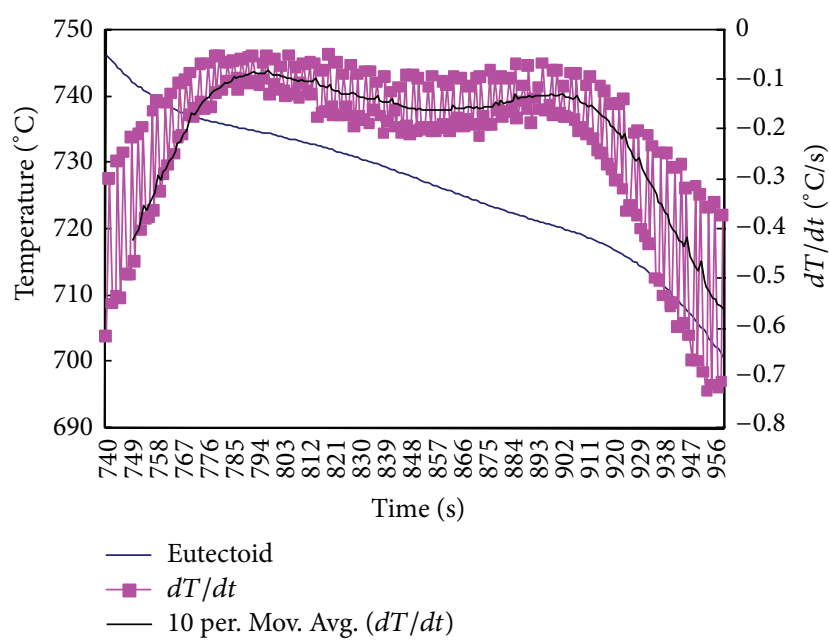

(c)

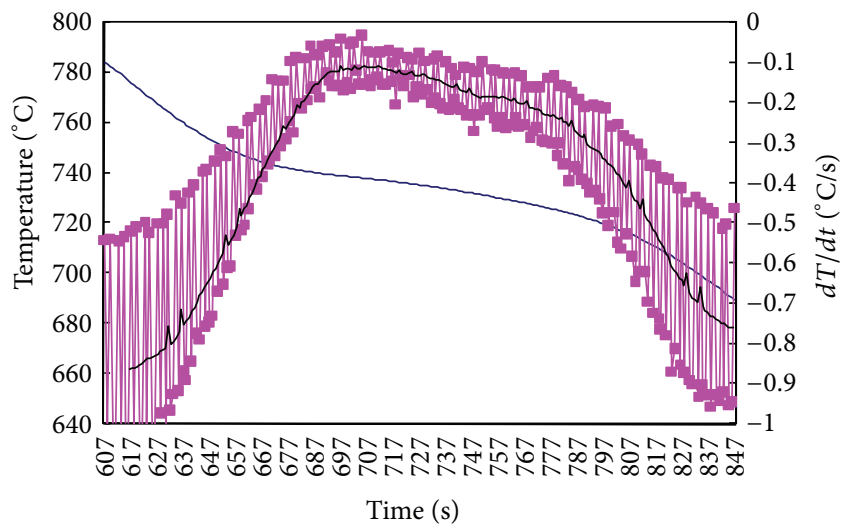

(b)

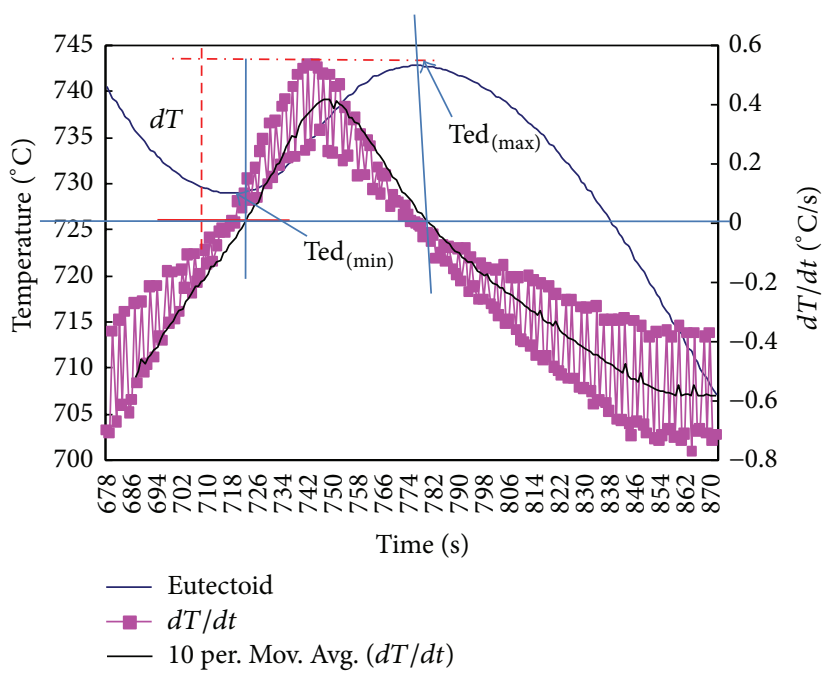

(d)

FIGURE 9: Magnified part of the cooling curves showing the change in the amount of eutectoid undercooling of the DI alloys (a) A, (b) B, (c) C, and (d) D.

step inoculation of alloys $\mathrm{B}$ and $\mathrm{D}$ using $0.5 \%$ inoculant increased $T_{\text {eu }}$ and $T_{\mathrm{Re}}$ by 7 degrees in case of alloy B. The presence of antimony in alloy $\mathrm{D}$ caused further increase in both of the temperatures up to 13 degrees as shown in Table 3. Double inoculation with larger amount of inoculant (1\%), alloy $\mathrm{C}$, showed lower $T_{\mathrm{eu}}$ and $T_{\mathrm{Re}}$ in comparison to alloy B. According to Ferroa et al. [12], the second solidification step (starting from $T_{\text {eu }}$ ) refers to the nucleation of secondary nodules and growth of the corresponding eutectic spheroidal graphite cells. Based on it, the double inoculation process can increase $T_{\text {eu }}$ and $T_{\mathrm{Re}}$ and this effect is decreased when larger amount of inoculant is added. The highest $T_{\mathrm{eu}}$ and $T_{\mathrm{Re}}$ recorded for $\mathrm{Sb}$ containing alloy are owed to the ability of $\mathrm{Sb}$ to support formation of typical nodules in heavy section ductile iron [8].

Figure 9 represents the eutectoid part of the cooling curves of alloys A, B, C, and D. It is clear that the eutectoid reaction in alloy $\mathrm{D}$ is different than that of the other alloys. The increased eutectoid undercooling denoted as $d T$ in Figure 9 is due to the formation of pearlite phase. It is known
TABLE 3: Cooling curve characteristics temperatures.

\begin{tabular}{lcc}
\hline Alloy & $T_{\mathrm{eu}}$ & $T_{\mathrm{Re}}$ \\
\hline $\mathrm{A}$ & 1140 & 1143 \\
$\mathrm{~B}$ & 1147 & 1150 \\
$\mathrm{C}$ & 1142.5 & 1152 \\
$\mathrm{D}$ & 1153 & 1157.5 \\
\hline
\end{tabular}

that $\mathrm{Sb}$ is a pearlite stabilizer [4] since it limits the diffusion of carbon from pearlite to graphite nodules as represented in the line scan of Figure 5.

\subsection{Mechanical Properties Evaluation}

3.3.1. Tensile Test. A considerably high yield strength and tensile strength with a minimum of $240 \mathrm{MPa}$ and $400 \mathrm{MPa}$, respectively, are required along with $18 \%$ elongation according to European Standard EN-GJS-400-18U-LT for windmill 


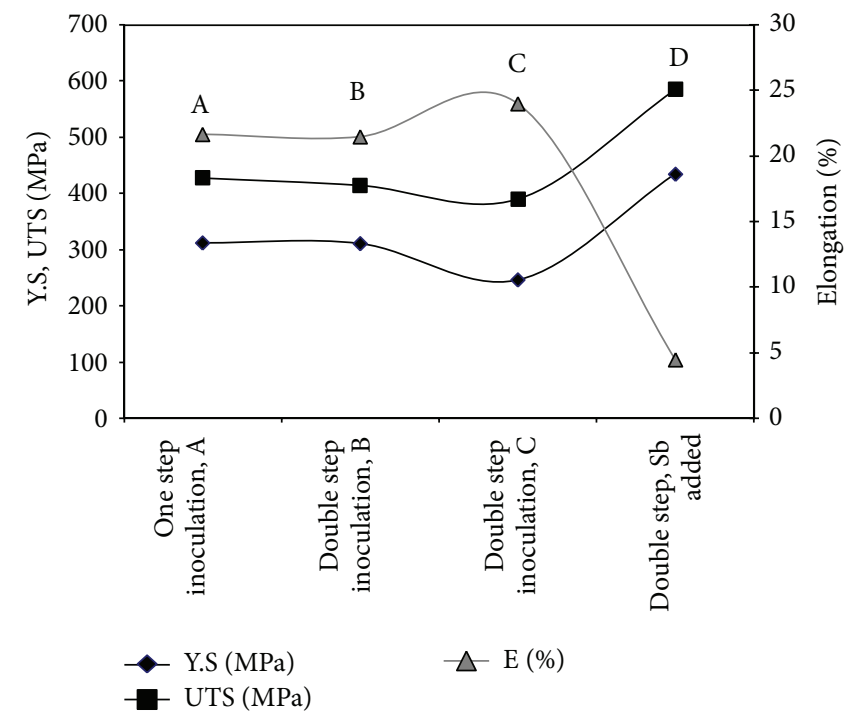

Figure 10: Tensile test results of the DI alloys (a) A, (b) B, (c) C, and D.

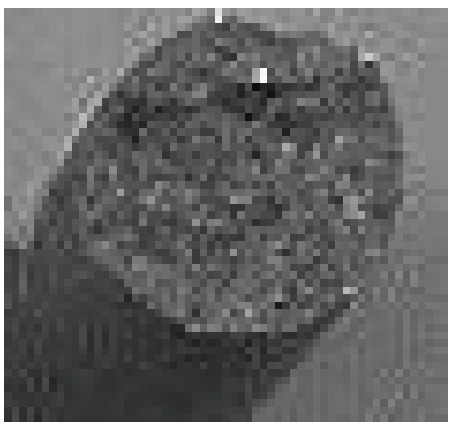

(a)

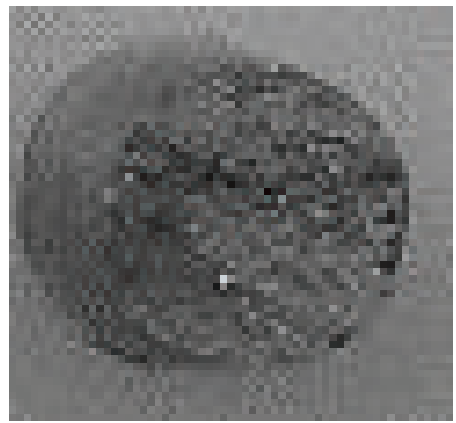

(c)

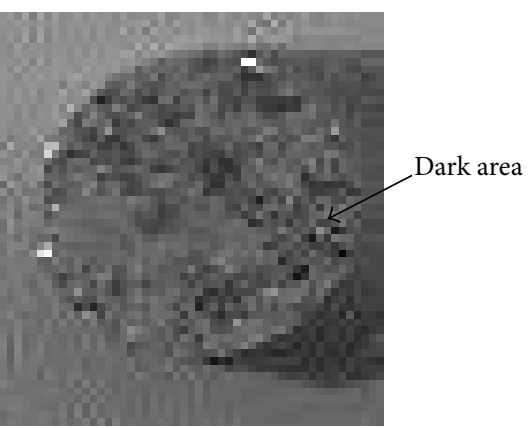

(b)

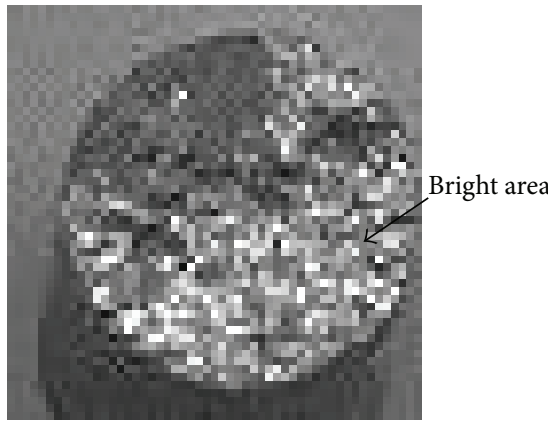

(d)

Figure 11: Macrostructure of the fracture surface of tensile samples of alloys (a) A, (b) B, (c) C, and (d) D.

DCI. The results of tensile test are shown in Figure 10 for A$\mathrm{D}$ samples. It is clear that there is no evident difference in the strength values of alloy $\mathrm{A}$ (one step inoculation, $0.5 \%$ inoculant) and alloy B (double step, $0.5 \%$ inoculant). Both of these alloys could meet the standard values of yield and tensile strength with an elongation exceeding 20\%. Alloy C (double step, $1 \%$ inoculants) with almost ferritic matrix showed relatively lower ultimate and yield strength values, while higher elongation of $24 \%$ was recorded. This increased elongation is due to the relative absence of pearlite. Though this alloy presented better graphite nodules characteristics compared to alloys A and B, Table 2, the strength decreased relatively in (double step, $1 \%$ inoculant) alloy C. A good yield, tensile strength, and fracture toughness are expected in the microstructure presenting $100 \%$ of ferrite due to the presence of silicon and manganese. Both elements harden and strengthen the ferrite and accordingly increase the yield and tensile strength [10]. However, in the current experiments, 


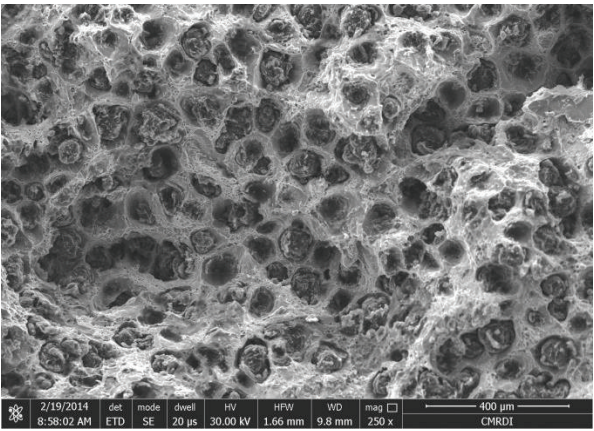

(a)

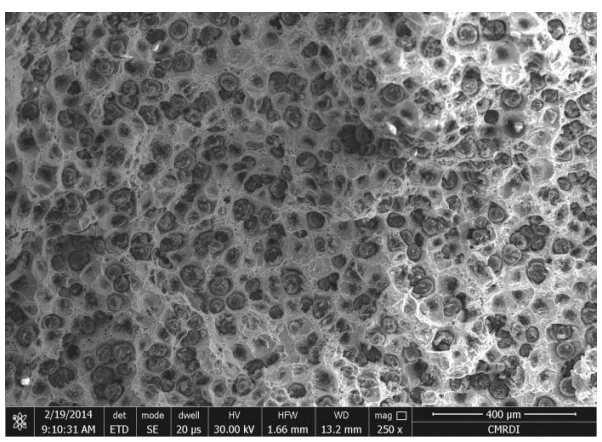

(c)

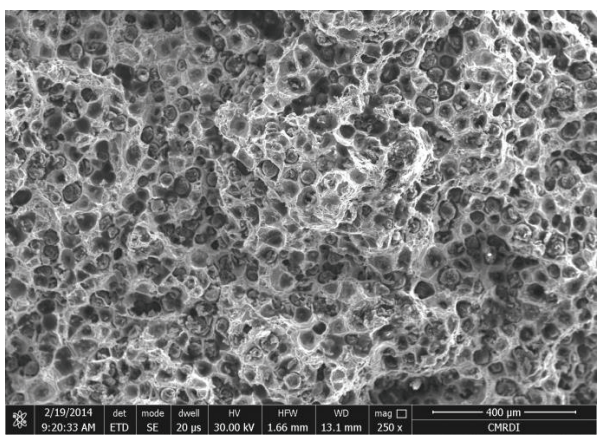

(e)

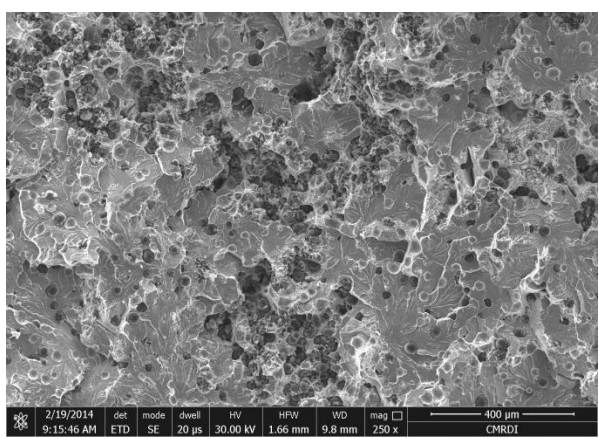

(g)

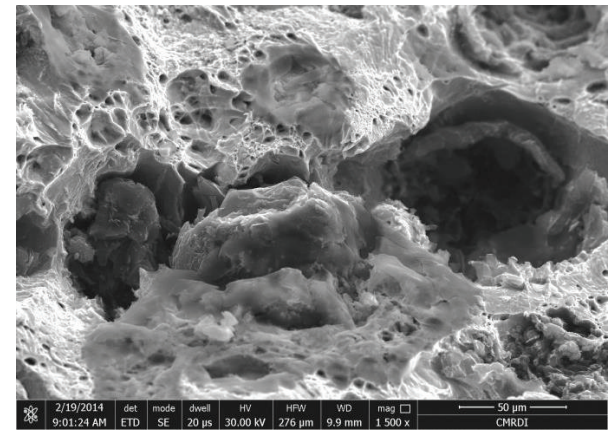

(b)

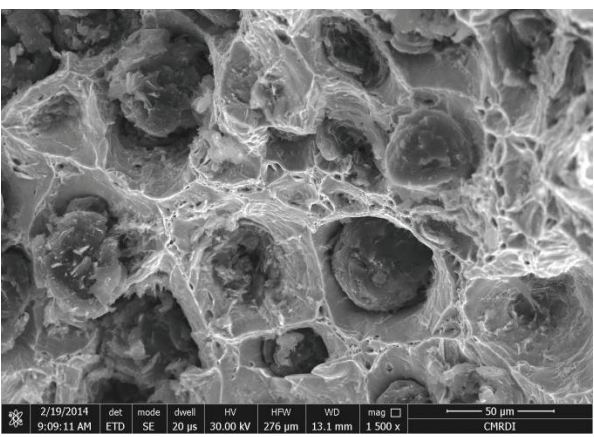

(d)

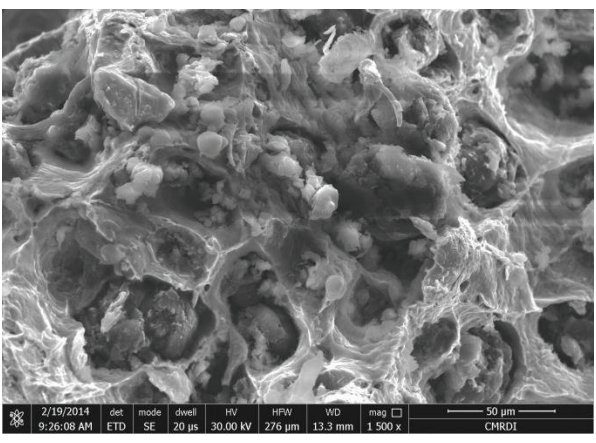

(f)

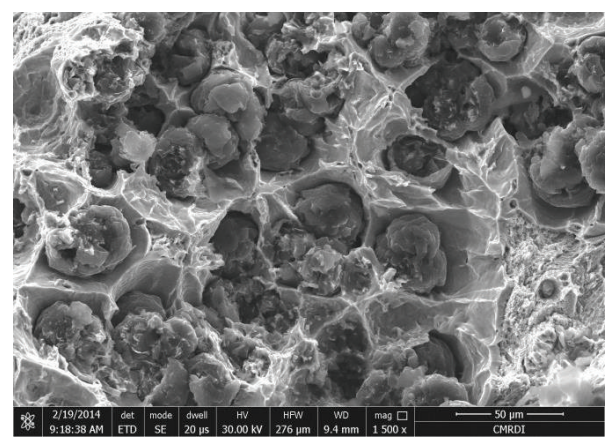

(h)

FigURE 12: Topography of the fractured tensile test samples at low and high magnification of alloy A ((a), (b)), alloy B ((c), (d)), alloy C ((e), $(\mathrm{f}))$, and alloy $\mathrm{D}((\mathrm{g}),(\mathrm{h}))$. 
the unintended decrease in the Si content to 2.16, Table 1, occurred. This can explain the unexpected reduction in the strength of alloy C.

In case of alloy $\mathrm{D}$, a significant increase in both of the yield and tensile strength was observed, Figure 10. The matrix in this microstructure, Figure 4(d), is almost pearlitic. It is well known that pearlite hardens the matrix and, at the same time, increased pearlite content enhances the resistance of the matrix [13]. In addition, presence of antimony (around 0.02\%) improves the graphite morphology and plays a significant role in increasing the graphite nucleation rate and inhibiting the deterioration of graphite nodules in heavy section ductile iron castings [14]. Therefore, the best nodularity (98\%) could be obtained in alloy D containing Sb, Table 2.

3.3.2. Failure Surface Analysis. The fracture surfaces of the tensile test samples were firstly analyzed with the naked eye. We observed that the fracture surface of alloy $\mathrm{D}$ is almost bright while that of alloys $\mathrm{A}, \mathrm{B}$, and $\mathrm{C}$ is relatively dark as shown in Figure 11. Both of these zones were then observed with a field emission microscopy and represented in Figure 12. A deep analysis of Figures 12(a)-12(h) indicates that different mechanisms of fracture have occurred. This difference in behavior of fracture was expected due to the difference in the matrix structure. Alloys A, B, and C have ferritic matrix, while matrix of alloy D is pearlitic, Figures 4(a)4(d). It was reported that the fracture mechanism is much related to the ferrite and pearlite content in as-cast ductile iron [15]. In the samples with ferrite matrix, the surface is composed of many fracture dimples. These small dimples observed in the fracture surface represent voids coalescence as shown in the magnified micrographs of Figures 12(b), 12(d), and 12(f). According to Figures 12(a)-12(f), there are different failure surfaces, indicating that failure mode seems to be ductile-brittle intergranular.

The topography of the sample, Figures $12(\mathrm{~g})$ and $12(\mathrm{~h})$, shows that small plastic deformation is observed. This deformation has to do with the brittle fracture that can be identified when observing the surface that fails. They revealed that cleavage has occurred in brittle fracture mode by cleavage (intragranular rupture). Concluding, the matrix structure of ductile cast iron always affects not only the strength and impact properties but also the fracture mode during testing.

3.3.3. Impact Toughness. In this paper, the study is focused on a heavy section ferritic ductile iron. The ferrite (alpha iron) has a good ductility (plasticity) and a very good ability to resist the impact energy at low temperatures. The presence of a small quantity of residual pearlite in the ferrite matrix may change the tensile properties and resilience of ductile iron. It increases material hardness and reduces the impact energy necessary to failure [15]. Also the impact properties of ferritic cast iron are affected by the quantity of graphite nodules and the nodularity; as the nodules become larger in size or its count increases, the mechanical properties decrease accordingly [16]. Based on it, we have two factors that influence the impact properties in the current study: the ferrite content and the graphite nodule features.

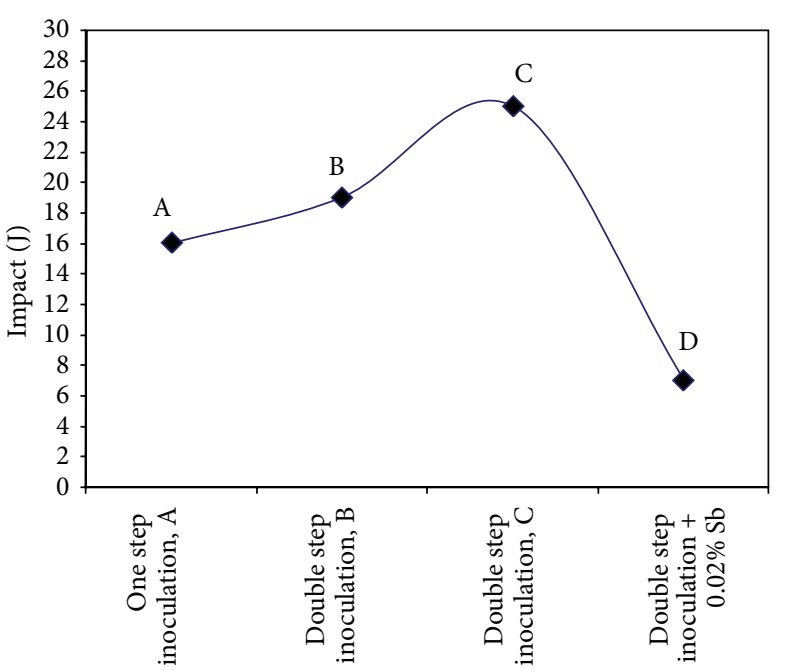

FIgURE 13: Impact toughness of alloys A, B, C, and D.

The results of impact toughness are shown in Figure 13 for the four tested samples. The impact toughness recorded for alloy A (one step inoculation, 0.5\%) was around $16 \mathrm{~J}$ and increased to $19 \mathrm{~J}$ for alloy B (double step inoculation, $0.5 \%)$. Here it is worth noting that the effect of increased graphite nodularity in alloy B compared to A (70-80\%) was translated to higher impact toughness. Though the pearlite content increased from 2 to $5 \%$ from alloy A to B, respectively, the improvement in graphite nodularity was more effective. Chaengkham and Srichandr [17] reported that the more the form of the graphite deviates from the ideal spherical shape, the more the ductility and strength decrease. This is due to stress concentration caused by the nonspherical nodules. In alloy C (fully ferritic matrix, 95\% nodularity), the impact value increased to around $25 \mathrm{~J}$, which was expected due to the ferritic matrix along with well rounded nodules. Considering the standard impact properties for windmill $\left(12 \mathrm{~J}\right.$ at $\left.-20^{\circ} \mathrm{C}\right)$, the three samples with ferrite matrix could achieve the standard. In contrast, sample D with almost pearlitic matrix showed very low impact energy of about $6 \mathrm{~J}$. Though this alloy has the highest nodularity ( 98\%), the presence of pearlitic matrix which is known to reduce the fracture toughness [10] was more effective. Therefore, the difficult challenge in the production of DI alloys for windmill is to obtain fully ferritic matrix while achieving the standard strength conditions [6].

\section{Conclusions}

In this study, some heavy section ductile cast iron castings were prepared in order to study the influence of different inoculation methods on microstructure and mechanical properties of these alloys. The following conclusions were derived.

(i) The best inoculation procedures in the current experiments in terms of graphite nodules characteristics and mechanical properties are double inoculation with $0.8 \%$ inoculants added at first and $0.2 \%$ in the late inoculation step. 
(ii) In antimony containing alloy, Sb showed a positive influence on controlling the growth of graphite nodules in the heavy section DCI castings; however low impact toughness was recorded.

(iii) The matrix structure of ductile cast iron showed a significant influence not only on the strength and impact properties but also on the fracture mode during testing.

\section{Conflict of Interests}

The authors declare that there is no conflict of interests regarding the publication of this paper.

\section{References}

[1] M. J. Fallon, "Experiences in the manufacture of ductile irons," The Foundryman, vol. 88, no. 9, pp. 308-318, 1995.

[2] G. K. Bouse, J. Parolini, N. Rojek, and C. Zhou, "Quality requirements for general electric ductile iron castings exceeding 10T used for wind and gas turbine components," in Proceedings of the 69th World Foundry Congress (WFC '10), vol. 3, Hangzhou, China, 2010.

[3] C. M. Ecob, A Review of Common Metallurgical Defects in Ductile Cast Iron, Elkem Foundry Products Division, Oslo, Norway, 2004.

[4] I. Riposan, M. Chisamera, S. Stan, and T. Skaland, "Surface Graphite Degeneration in Ductile Iron Castings for Resin Molds," Tsinghua Science and Technology, vol. 13, no. 2, pp. 157163, 2008.

[5] Rio Tinto Iron \& Titanium, Ductile Iron Data for Design Engineers, Rio Tinto Iron \& Titanium, Montreal, Canada, 1990.

[6] H. Roedter and M. Gagne, "Ductile iron for heavy section windmill castings," in Proceedings of the Keith Millis Symposium on Ductile Cast Iron, pp. 176-182, 2003.

[7] H. Bakkerus and B. J. van der Holst, "Dutch develop vortex process for ductile iron treatment," Modern Casting, vol. 71, no. 3, pp. 41-44, 1981.

[8] L. Zhe, C. Weiping, and D. Yu, "Influence of cooling rate and antimony addition content on graphite morphology and mechanical properties of a ductile iron," China Foundry, vol. 9, no. 2, pp. 114-118, 2012.

[9] http://www.foundry.elkem.com/.

[10] A. Alhussein, M. Risbet, A. Bastien, J. P. Chobaut, D. Balloy, and J. Favergeon, "Influence of silicon and addition elements on the mechanical behavior of ferritic ductile cast iron," Materials Science and Engineering A, vol. 605, pp. 222-228, 2014.

[11] L. Zhenhua and L. Yanxiang, "Effect of Sb on the graphite morphology and mechanical properties in heavy section ductile iron," Materials Science Forum, vol. 475-479, pp. 2769-2772, 2005.

[12] P. Ferroa, A. Fabrizi, R. Cervob, and C. Carollo, "Effect of inoculant containing rare earth metals and bismuth on microstructure and mechanical properties of heavy-section near-eutectic ductile iron castings," Journal of Materials Processing Technology, vol. 213, no. 9, pp. 1601-1608, 2013.

[13] R. A. Gonzaga, P. Martínez Landa, A. Perez, and P. Villanueva, "Mechanical properties dependency of the pearlite content of ductile irons," Journal of Achievements in Materials and Manufacturing Engineering, vol. 33, no. 2, pp. 150-158, 2009.
[14] R. A. Gonzaga, "Influence of ferrite and pearlite content on mechanical properties of ductile cast irons," Materials Science and Engineering: A, vol. 567, pp. 1-8, 2013.

[15] W. L. Bradley and M. N. Srinivasan, "Fracture and fracture toughness of cast irons," International Materials Reviews, vol. 35, no. 1, pp. 129-161, 1990.

[16] M. Shirani and G. Härkegård, "Large scale axial fatigue testing of ductile cast iron for heavy section wind turbine components," Engineering Failure Analysis, vol. 18, no. 6, pp. 1496-1510, 2011.

[17] P. Chaengkham and P. Srichandr, "Continuously cast ductile iron: processing, structures, and properties," Journal of Materials Processing Technology, vol. 211, no. 8, pp. 1372-1378, 2011. 

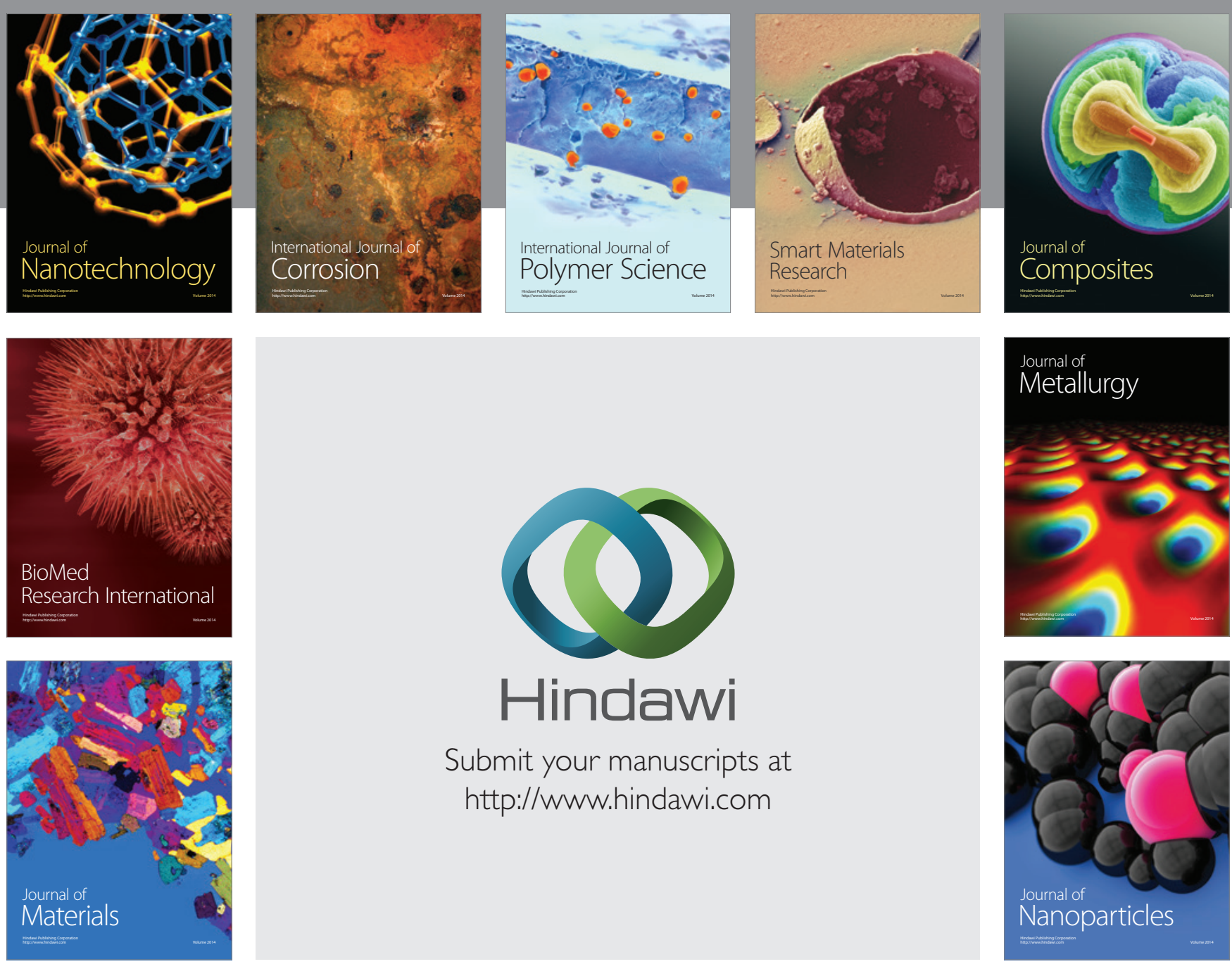

Submit your manuscripts at http://www.hindawi.com
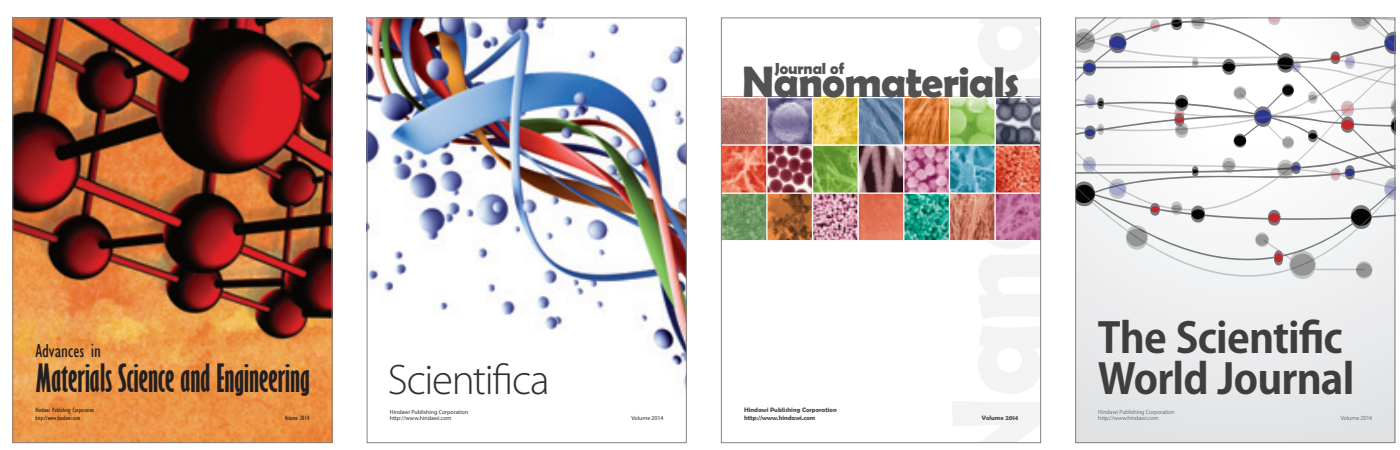

\section{The Scientific World Journal}
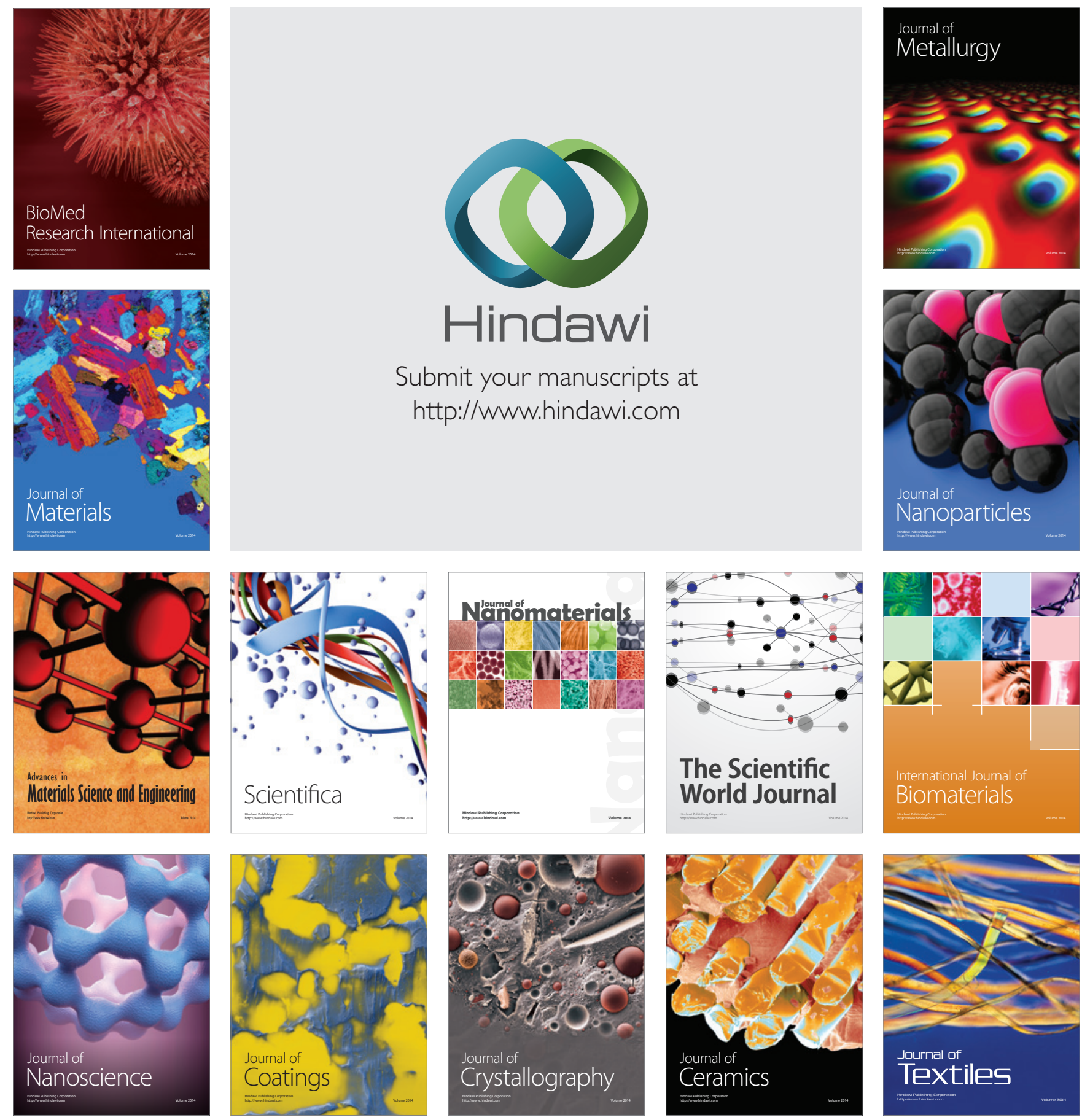